\title{
Differential proteomics analysis of Frankliniella occidentalis immune response after infection with Tomato spotted wilt virus (Tospovirus)
}

Pamella Akoth OGADA $^{\mathrm{a}^{*}}$, Leonard Muriithi KIIRIKA ${ }^{\mathrm{b}}$, Christin LORENZ $^{\text {cd }}$, Jennifer SENKLER $^{\mathrm{d}}$, Hans-Peter BRAUN ${ }^{\mathrm{d}}$, Hans-Michael POEHLING ${ }^{\mathrm{a}}$

${ }^{a}$ Department of Phytomedicine, Institute of Horticultural Production Systems, Gottfried Wilhelm Leibniz Universität Hannover, Herrenhäuser Strasse 2, 30419 Hannover, Germany.

${ }^{b}$ Department of Plant Molecular Biology, Institute of Plant Genetics, Gottfried Wilhelm Leibniz Universität Hannover, Herrenhäuser Strasse 2, 30419 Hannover, Germany.

${ }^{c}$ Leibniz-Institut für Analytische Wissenschaften - ISAS - e.V.,Otto-Hahn-Straße 6b, 44227 Dortmund, Germany.

${ }^{d}$ Department of Plant Proteomics, Institute of Plant Genetics, Gottfried Wilhelm Leibniz Universität Hannover, Herrenhäuser Strasse 2, 30419 Hannover, Germany.

\section{*Author for correspondence:}

Pamella Akoth Ogada

Tel: +: +49511 7622643

Fax: +49 5117623015

Email: ogada@ipp.uni-hannover.de

Key words: Innate immunity; Frankliniella occidentalis; proteomics; Tomato spotted wilt virus; 2D-IEF/SDS/PAGE, mass spectrometry

Word count for abstract: 150 


\begin{abstract}
Tomato spotted wilt virus (TSWV) is mainly vectored by Frankliniella occidentalis Pergande, and it potentially activates the vector's immune response. However, molecular background of the altered immune response is not clearly understood. Therefore, using a proteomic approach, we investigated the immune pathways that are activated in F. occidentalis larvae after 24 hours exposure to TSWV. Two-dimensional isoelectric focusing/sodium dodecyl sulfate polyacrylamide gel electrophoresis (2D-IEF/SDS/PAGE) combined with mass spectrometry (MS), were used to identify proteins that were differentially expressed upon viral infection. High numbers of proteins were abundantly expressed in F. occidentalis exposed to TSWV (73\%) compared to the non-exposed (27\%), with the majority functionally linked to the innate immune system such as: signaling, stress response, defense response, translation, cellular lipids and nucleotide metabolism. Key proteins included: $70 \mathrm{kDa}$ heat shock proteins, Ubiquitin and Dermcidin, among others, indicative of a responsive pattern of the vector's innate immune system to viral infection.
\end{abstract}

\title{
1 Introduction
}

Tomato spotted wilt virus (TSWV) is the type species of the genus Tospovirus; family Bunyaviridae. It is transmitted exclusively by multiple thrips species (Whitfield et al., 2005) (Ullman et al., 1997), with Frankliniella occidentalis (Pergande) being the main and the most efficient vector (Riley and Pappu, 2004)(Wijkamp et al., 1995)(Whitfield et al., 2005). This specificity of the virus-vector interaction is governed by receptor based endocytosis allegedly involving surface receptor proteins reported in F. occidentalis and linked to the recognition of TSWV (P. Ogada et al., 2016)(de Medeiros et al., 2000)(Kikkert et al., 1998)(Bandla et al., 1998). Furthermore, evidence exists of involvement of viral glycoproteins as determinants in the recognition process in the vector's midgut (Naidu et al., 2008)(Whitfield et al., 2008). 
After acquisition by $F$. occidentalis, TSWV replicates and circulates inside the host midgut, the virus is passed via cell to cell movement from the midgut lumen through the midgut cell wall into the haemocoel and finally to the salivary glands where it replicates further during thrips development ((Whitfield et al., 2005)(Nagata et al., 1999)(Nagata et al., 2002)(Ullman et al., 1993)(Moritz et al., 2004). The replication of the virus within the host suggests a likelihood for pathological (lethal) effects as well as changes in the vector's physiology which may influence the performance and fitness negatively (Stumpf and Kennedy, 2007)(Nault, 1994). Conversely, recent studies have reported that feeding of $F$. occidentalis on TSWV infected host plants resulted in improvement in fitness: in terms of improved survival and reduced development time (Stafford et al., 2011)(Shrestha et al., 2012)(Ogada et al., 2013)(Shalileh et al., 2016)(P. A. Ogada et al., 2016), assuming a triggered innate immune response to TSWV infection (de Medeiros et al., 2004). Therefore, we initiated a pilot study to investigate the immune response of $F$. occidentalis to infection with TSWV, using proteomic analysis tools to identify differentially expressed proteins. We hypothesized that defense related proteins are activated in F. occidentalis in response to TSWV infection.

\section{Materials and Methods}

\subsection{TSWV isolate}

TSWV isolate (TSWV-N12) was obtained from the laboratory of virology, Wageningen University, the Netherlands. The maintenance and the detection of the TSWV isolate was done according to Ogada et al. (2013). The infected plants were maintained at $28-30{ }^{\circ} \mathrm{C}$ (greenhouse conditions) and served as inoculum source for further series of mechanical inoculation, as well as virus source for acquisition by $F$. occidentalis in the experiment.

\section{$2.2 \quad$ F. occidentalis culture}

F. occidentalis (F.o. 2), was also acquired from the laboratory of virology, Wageningen University, the Netherlands. A virus free stock culture was established on bean plants 
(Phaseolus vulgaris L.) in thrips proof cages maintained at climate chamber conditions $(25 \pm 2$ ${ }^{\circ} \mathrm{C}, 60-70 \%(\mathrm{RH})$ and $\left.16: 8 \mathrm{~h}(\mathrm{~L}: \mathrm{D})\right)$. From the stock culture, a synchronized rearing was developed as describe in Ogada et al. (2013). Both the stock culture and the synchronized rearing were maintained in separate climate cabins completely isolated from any other sources of thrips.

\subsection{TSWV acquisition by $F$. occidentalis and sample preparation}

At least 300 of $<12$ hours old F. occidentalis larvae (L1) were introduced on C. annuum leaflets that were either healthy or heavily infected with TSWV (confirmed by DAS-ELISA). The virus infected or healthy leaflets were individually placed in a $15 \mathrm{~cm} \varnothing$ petri dish layered with moistened gypsum $\left(\mathrm{CaSO}_{4}\right.$ and charcoal 9:1 ratio), followed by the introduction of newly hatched L1 larvae for an acquisition access period (AAP) of 24 hours. The petri dishes were carefully sealed to avoid any escape of $F$. occidentalis. After the AAP, approximately $250 \mathrm{~L} 1$ larvae were collected into a $2 \mathrm{ml}$ Eppendorf tube for each treatment using a fine paint brush, shock frozen in liquid nitrogen and then pulverized into fine powder using a bead mill pulverizer machine.

\subsection{Protein isolation: Phenol extraction method}

Total soluble proteins were extracted according to Colditz et al. (2004). The pulverized insect materials were homogenized in extraction buffer $(700 \mathrm{mM}$ sucrose, $500 \mathrm{mM}$ Tris, 50 mM EDTA, $100 \mathrm{mM} \mathrm{KCl,} \%$ (v/v) $\beta$-mercaptoethanol and $2 \mathrm{mM}$ PMSF, pH adjusted to 8.0). Then saturated phenol ( $\mathrm{pH}$ 6.6/7.9; Amresco, Solon, USA) was added. This was followed by several rounds of centrifugation before the proteins were precipitated using $0.1 \mathrm{mM}$ ammonium acetate in methanol and then incubated at $-20{ }^{\circ} \mathrm{C}$ overnight. The solution was again centrifuged, and then the pellet was re-suspended in $80 \%$ acetone solution, followed by final centrifugation. The resulting pellet was air dried at room temperature and then weighed. 


\subsection{Two-dimensional isoelectric focusing/sodium dodecyl sulfate polyacrylamide gel electrophoresis (2D-IEF/SDS-PAGE)}

From the resulting protein pellet, $5 \mathrm{mg}$ were re-suspended in rehydration buffer $(8 \mathrm{M}$ Urea, $2 \mathrm{M}$ thiourea, $2 \%$ (w/v) CHAPS, a trace of bromophenol blue, $\mathrm{ddH}_{2} \mathrm{O}, 100 \mathrm{mM}$ DTT, $12 \mu \mathrm{l} / \mathrm{ml}$ DeStreak-reagent, $0.5 \%$ (v/v) IPG-buffer pH 3-11 NL, GE Healthcare, Freiburg, Germany) and directly loaded onto an IPG strip $(18 \mathrm{~cm}, \mathrm{pH} 3-11$ non-linear (NL), GE Healthcare, Freiburg, Germany). Isoelectric focusing was performed as described in Mihr and Braun (2003). The IPG strips were equilibrated twice for 15 min each time, first by immersing them in equilibration buffer (6 M urea, $50 \mathrm{mM}$ Tris- $\mathrm{HCl}(\mathrm{pH} 8.8), 30 \%$ glycerol and 2\% SDS) with DTT $(1 \%, w / v)$ to reduce the cysteine residues, and then in equilibration buffer with iodoacetamide $4 \%(\mathrm{w} / \mathrm{v})$, for informal alkylation of cysteine residues. For the second gel dimensions, the equilibrated strips were shortly rinsed in tricine gel buffer ( $3 \mathrm{M}$ Tris- $\mathrm{HCl}, \mathrm{pH}$ $8.45,0.3 \%$ SDS). The IPG strips were then carefully fixed horizontally onto $12 \%$ acrylamide SDS gels. The gel run was performed for $18 \mathrm{~h}$ at $30 \mathrm{~mA}$ per gel using the Bio-Rad Protean II XL gel system (Biorad, München, Germany). The two-dimensional gel electrophoresis for TSWV exposed and non-exposed $F$. occidentalis were repeated at least three times for the 3 biological replicates.

\subsection{Gel staining procedure}

Fixing of all the 2D gels was done using $10 \%(\mathrm{v} / \mathrm{v})$ acetic acid in $15 \%(\mathrm{v} / \mathrm{v})$ ethanol for 2 hours, then stained overnight with Coomassie blue CBB G-250 (Merck, Darmstadt, Germany) as described by Neuhoff et al. (1985; 1990). The gels were then de-stained several times using $\mathrm{ddH}_{2} \mathrm{O}$ before being scanned on a UMAX Power Look III Scanner (UMAX Technologies, Fremont, CA, U.S.A.). 


\subsection{Quantitative gel analysis of the differentially expressed proteins}

The gel scans were evaluated using Delta2D software, version 4.3 (Decodon, Greifswald, Germany) as described in Berth et al. (2007) and Lorenz et al. (2014). Three replicates per treatment $(F$. occidentalis exposed or non-exposed to TSWV) were used (Supplementary data, Fig. 1A). Spot detection was done automatically with minor manual corrections of obvious gel disturbances. Delta2D software was used for in-gel normalization of the overlays of three replicate gels per treatment (Supplementary data, Fig. 1B). Significant variation in spot volumes between the exposed and the non-exposed $F$. occidentalis gels was determined using a Student's t.-test $(p$-value $\leq 0.05)$ based on the normalized relative spot volume. Spots differing in volume were color coded according to their respective treatment (Supplementary data, Fig. 1C). A true difference in protein abundance was considered only if the variation in spot volumes between the compared treatments had a factor $\geq 1.5$. Protein spots with significant variation in volume were subsequently identified by mass spectrometry.

\subsection{Protein identification by mass spectrometry}

Analyses of the differentially expressed proteins between treatments were based on proteins identified by mass spectrometry (MS). Tryptic digestion and MS analysis were performed according to Klodmann et al. (2010) using the EASY-nLC System (Proxeon) coupled to a MicroTOF-Q II mass spectrometer (Bruker Daltonics, Bremen, Germany). Protein identification was carried out using the MASCOT search algorithm (www.matrixscience.com) against the (i) Ensembl Metazoa (www.metazoa.ensembl.org), (ii) Flybase (www.flybase.org), (iii) SwissProt (www.uniprot.org) and (iv) NCBInr (www.ncbi.nig.gov) databases.

A schematic of the experimental workflow is shown in Supplementary data, Fig. 2. 


\section{Results and Discussion}

Evaluation of Delta2D for changes in the $F$. occidentalis L1 proteome after 24-hour exposure to TSWV revealed 901 differentially expressed spots, but only 30 showed significant variations in volume according to a $p$-value of $\leq 0.05$ based on the normalized relative spot volume (Fig. 1). Out of the 30 spots, 22 increased in volume in response to TSWV while 8 decreased in volume (Supplementary data, Table 1 and 2). Proteins in spots that significantly changed in volume (Fig. 1) were analysed by mass spectrometry. However, this experimental approach did not allow the quantification of the changes in abundance for individual enzymes because most spots on the 2D gels included more than one protein. Nevertheless, in some cases, quantitative changes were visible for individual proteins, and in several others tendencies could be seen. The names and physiological background of the identified proteins are given in Table 1. Furthermore, an interactive gel-map is available online (www.gelmap.de/1290 password: FoProt) which summarizes Fig. 1 and Table 1.

Due to the absence of $F$. occidentalis immune related protein sequence databases, most proteins were identified via protein sequences of other insects which included: Drosophila spp (64\%), Anopheles gambiae (5\%), Ceratitis capitata (9\%), Lysiphlebus testaceipes (5\%), Sarcophaga peregrine (5\%), Bactrocera dorsalis (9\%) and Vespula vulgaris (5\%), as well as other metazoan sequences (Supplementary data, Fig. 3). Furthermore, majority of studies on the invertebrate innate immune system have been on Drosophila as the model organism, making it the main reference point with regards to the available information and sequence databases (Barillas-Mury et al., 2000)(Hoffmann et al., 1999).

During virus recognition and infection process, key proteins are involved which have to be considered when discussing the vector's innate immune response to viral infections. In this study, we classified the identified proteins according to their functional groups (Figure 1, Table 1). Of the proteins that were found to be significantly increased in abundance in response to the virus; $26 \%$ were identified to be involved in translation, $15 \%$ in insect defense 
response, $13 \%$ in signaling pathways, another $13 \%$ in anatomical development, $9 \%$ in cellular lipid metabolic processes $\left(\mathrm{NADP}^{+}\right), 8 \%$ were structural proteins, another $8 \%$ were linked to stress response, 5\% involved in nucleotide metabolism and 3\% were actin binding proteins (Supplementary data, Fig. 4). On the other hand, 63\% of the proteins that were significantly decreased in abundance were structural proteins, $17 \%$ are involved in energy metabolism, $8 \%$ in amino acid metabolism, $4 \%$ in protein processing, another $4 \%$ in sugar metabolism and another $4 \%$ involved in cell cycle (Supplementary data, Fig. 5).

The primary immune components in invertebrates are mainly found within the hemolymph and are involved in virus recognition as well as initiation of defense responses (Christensen et al., 1989)(Paskewitz and Christensen, 1996). Some of the most abundantly increased proteins in F. occidentalis after TSWV infection included: Fibrinogen alpha chain protein, which is a ligand for the Toll-like receptor 4 (TLR4), which recognizes pathogen-associated molecular patterns (PAMPs) expressed by the virus and mediates the production of cytokines necessary for the development of effective immunity, by initiating signal transduction events induced by the pathogen, leading to blood coagulation and melanization reported in vertebrates (Cerenius et al., 2010)(Lavine and Strand, 2002)(Hoffmann and Reichhart, 2002)(Waltenbaugh et al., 2008). This reaction is well studied in mammals, however, whether or not a comparable coagulation process in insect hemolymph is involved in host defense is not yet confirmed (Cerenius et al., 2010)(Lavine and Strand, 2002)(Hoffmann and Reichhart, 2002). Studies on Helicoverpa zea larvae infected with Autographa californica polyhedrovirus, indicated that such circulating haemocytes encapsulate and kill the invading pathogen (Washburn et al., 1996). Also, inhibition of virus survival in F. occidentalis hemolymph has been reported and linked to the potential barriers to virus replication within the hemolymph. Thus, the mechanism of TSWV movement within the vector's body remains unknown (Nagata et al., 1999)(Whitfield et al., 2005). 
Heat shock cognate protein 70kDA (Hsp70); a ligand for the Toll-like receptor 2 (TLR2) (whose function is similar to the TLR4), was abundantly increased, and is associated with an antiviral autophagy dependent on the Toll signaling pathways in F. occidentalis, in response to stress as a result of exposure to TSWV. Autophagy: the natural catabolic process dependent on the cytosolic lysosome, is constitutively competent to destroy infectious viruses and essential viral components that link viral detection to the signaling of the antiviral innate immunity (Richetta et al., 2013)(Mizushima, 2007). It is also reported to be crucial for antiviral defense in insects (Shelly et al., 2009). The three types of autophagy pathways include: macroautophagy, microautophagy and chaperone-mediated autophagy (CMA), all taking part in the immune response (Mizushima, 2007). CMA is very specific and complex, involving recognition by the 70kDA heat shock cognate protein (Hsp70)-containing complex (Česena et al., 2012)(Bandyopadhyay et al., 2008). The pathway is triggered upon viral recognition independent of viral replication. In Drosophila, it is triggered upon recognition of the VSV-G (Nakamoto et al., 2012). The Hsp 70 act as chaperones which enable the cell to cope with the harmful aggregation of denatured proteins due to stress. They are associated with the CMA which is reported to be active at all times in different tissues in mammals and almost all cell types in culture studies, but highly triggered in response to stresses and variation in nutritional status of the cell (Cuervo et al., 1995).

TLR4 and TLR2 have been reported to detect several viral glycoproteins (Akira et al., 2006). For instance, in mammals, since the TLRs are known pattern recognition receptors (PRRs), Vesicular stomatitis virus glycoprotein (VSV-G) was previously reported to induce antiviral response dependent on TLR4 signaling (ligands include several viral proteins) (Georgel et al., 2007) which activates the immune system. Additionally, the envelope protein of Mouse mammary tumor virus (MMTV) activates TLR4 (Burzyn et al., 2004). Viruses or viral components such as Human cytomegalovirus (HCMV), Herpes simplex virus 1 (HSV-1) and Measles virus (MV) hemagglutinin protein have been reported to activate TLR2 (Bieback 
et al., 2002)(Compton et al., 2003). Therefore, we can conclude that the stimulation of proteins which function as ligands for the TLR2 (Hsp 70) and TLR4 (Fibrinogen alpha chain protein) in F. occidentalis in response to infection by TSWV, which is enveloped with glycoproteins, is an antiviral response in the host innate immune system.

Additionally, TLR 2 and TLR 4 mediate the production of cytokines which are expressed abundantly in the peripheral haemocytes, and are responsible for the mediation of the host response to pathogen intrusion via stimulation of nuclear factor Kappa-light-chainenhancer of activated B cells (NF-кB) (Hayden et al., 2006)(Doyle and Neill, 2006). NF-кB is a protein complex which belongs to the category of "rapid-acting" primary transcription factors, as it is found in almost all animal cell types in an inactive state and do not require new protein synthesis in order to become activated. This makes it one of the primary responders to harmful cellular stimuli. The finding that the stimulation of TLRs leads to the activation of $\mathrm{NF}-\kappa \mathrm{B}$, brings further understanding on how different pathogens activate NF- $\kappa \mathrm{B}$ (Hayden et al., 2006).

The processing of the NF- $\kappa \mathrm{B}$ is mediated by the ubiquitin-proteasome pathway which involves selective degradation of their C-terminal region containing ankyrin repeat motifs of the NF- $\kappa \mathrm{B}$ inhibitor $(\mathrm{I} \kappa \mathrm{B})$ (Karin and Ben-neriah, 2000). The I $\mathrm{KB}$ degradation is triggered in response to stimuli, such as those transduced in TLR activation, which potentiate NF- $\kappa B$ dimer activation in a non-canonical pathway (Basak et al., 2007)(Lo et al., 2006). This process of NF- $\kappa B$ activation occurs solely via the activation of an I $\mathrm{B}$ Kinase (IKK), which

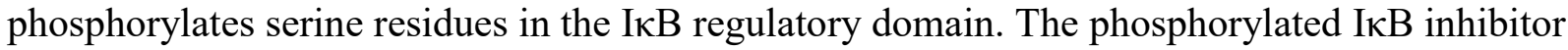
molecules are then modified by a process called ubiquitination, leading to their degradation by a cell structure called proteasome, thus freeing NF- $\mathrm{NB}$ to enter the nucleus where it triggers the expression of specific genes leading to immune response (Nelson et al., 2004)(Livolsi et al., 2001). 
Proteins linked to the ubiquitin-proteasome pathway: Ubiquitin, Valosin-containing interacting protein 135 (VCIP135) and Ubiquitin carboxyl-terminal hydrolase 36, were significantly increased in $F$. occidentalis after exposure to TSWV. Ubiquitin was the most significantly increased protein in terms of abundance after $F$. occidentalis exposure to TSWV (24 fold). It forms the main component of the ubiquitin-proteasome pathway which involves several sequential ATP-dependent enzymatic cascades (Wilkinson et al., 2005)(Komander and Rape, 2012)(Kimura and Tanaka, 2010). Ubiquitination or ubiquitilation refers to the addition of ubiquitin to a substrate protein, which may affect the protein in many ways, like signaling for its degradation via the proteasome, affect its cellular location and activity, as well as prevent or promote protein-protein interactions (Glickman and Ciechanover, 2002)(Mukhopadhyay and Riezman, 2007)(Papers et al., 2003). Only poly-ubiquitination at a defined lysine molecule is linked to the degradation by the proteasome, while the monoubiquitinations are involved in the regulation of processes such as translation, inflammation, endocytic trafficking and DNA repair (Mcdowell and Philpott, 2013). Additionally, unanchored-polyubiquitin has also distinct roles such as activation of protein kinases, and signaling. However, the other proteins, VCIP135 and Ubiquitin carboxyl-terminal hydrolase 36, are involved in the de-ubiquitination process in the ubiquitin-proteasome pathway, which leads to the activation of ubiquitin by cleaving of the inactively expressed form of ubiquitin (Turcu et al., 2009).

A-kinase anchor protein 3 which functions as a regulator of protein kinase A signaling cascade, as well as a transmembrane receptor protein of serine/threonine kinase signaling pathway, was also significantly increased in $F$. occidentalis after exposure to TSWV. The pathway involves a series of molecular signals initiated by the binding of an extracellular ligand to a receptor on the surface of the target cell regulating programmed cell death (apoptosis), cell differentiation, among others, by phosphorylating the $\mathrm{OH}$ group of serine or 
threonine (Vijayaraghavan et al., 1999). Another immune related protein that was significantly increased is Dermcidin (10 fold). It has antimicrobial activities and promotes natural cell survival under severe stress (Zeth, 2013). The proposed mechanism for the antimicrobial activities includes an ion gradient decoupling across biological membranes, and proteolytic activity (Song et al., 2013). Heterochromatin protein 1, a stress response protein, was also increased in abundance in $F$. occidentalis after exposure to TSWV. Its main function is the repression of transcription by altering the structure of chromatin, also referred to as chromatin silencing e.g. by conversion of large regions of DNA into an inaccessible state often called heterochromatin (Vermaak and Malik, 2009). Additionally, DNA repair protein REV1 and Inactive hyaluronidase protein, both of which are linked to the host defense response, were increased abundantly in response to TSWV infection. Inactive hyaluronidase proteins are usually triggered in response to the invasion by foreign bodies or injury, leading to restriction of damage to the tissue attacked or prevention/recovery from the infection, while DNA repair protein REV1 is required for the induction of mutations as a form of immune reaction in response to physical and chemical agents (UniProtKB/Swiss-Prot, 2015).

Increase in abundance of the structural proteins and those involved in anatomical development, in response to viral infection, could be associated with the rapid growth and development reported in $F$. occidentalis after exposure to TSWV (Belliure et al., 2005)(Belliure et al., 2008)(Ogada et al., 2013)(Shalileh et al., 2016). Additionally, the proteins associated with translation that were increased abundantly in response to TSWV could be linked to the replicating virus within the (Stumpf and Kennedy, 2007)(Nault, 1994). For instance, Eukaryotic translation initiation factor 5A-1, one of the abundantly increased translation protein in this study, is an mRNA-binding protein, involved in the regulation of mRNA turnover by controlling the actin dynamics and cell cycle progression (RNA decay). It is also involved in stress response and maintenance of cell integrity. Additionally, it regulates 
TNF-alpha-mediated apoptosis (UniProtKB/Swiss-Prot, 2015). Moreover, the proteins involved in cellular lipids and nucleotides metabolic processes that were abundantly increased in F. occidentalis after exposure to TSWV, could also be associated with the replicating virus in the vector (Stumpf and Kennedy, 2007)(Nault, 1994). For example, Guanine nucleotidebinding subunit beta-like protein, which is involved in nucleotide metabolism, functions by recruiting, assembling and/or regulating of a variety of signaling molecules. It is also involved in the positive regulation of viral genome replication by the host, which is initiated in response to viral infection. This selective mRNA translation opens up a target for the development of broad antiviral intervention in the host (Majzoub et al., 2014).

The use of L1s of F. occidentalis which were not exposed to TSWV, enabled us to clearly identify the differentially expressed proteins in response to viral infection. The proteins that were decreased in abundance in TSWV exposed $F$. occidentalis, were clearly those proteins which are basically involved in the normal anatomical growth and development of $F$. occidentalis. Thus, we can conclude that thee differentially expressed proteins are naturally present at basal levels in expression and are involved in multifaceted roles in the invertebrate physiology, but they are only activated significantly in response to stress or pathogen attack (Badillo-Vargas et al., 2012).

Despite being able to see clearly the involvement of immune related proteins in response to viral infection, the use of other Metazoan databases in the functional description of the differentially expressed protein in F. occidentalis, only offers basic information. Availability and use of $F$. occidentalis transcriptome database related to the innate immune system would enable a more specific and detailed analysis. We can therefore conclude that, the hereby presented results indicate that the exposure of $F$. occidentalis to TSWV triggers production of certain proteins which are associated with the innate immune response of the vector to viral infection. This substantiates the research findings that have reported improved fitness in $F$. 
occidentalis exposed to TSWV, and thus, improving our understanding to the complex virusvector-host plant interaction.

\section{Acknowledgements}

This research was funded by German Research Foundation (DFG - Deutsche Forschungsgemeinschaft) Project number: 207/37-1. We thank the Wageningen University, the Netherlands for the supply of $F$. occidentalis and the TSWV isolates, also the entire technical support team, departments: Phytomedicine and Proteomics, Leibniz Universität, Hannover.

We declare no conflict of interest among the authors of this paper.

\section{References}

Akira, S., Uematsu, S., Takeuchi, O., 2006. Pathogen Recognition and Innate Immunity. Cell 124, 783-801. doi:10.1016/j.cell.2006.02.015

Badillo-Vargas, I.E., Rotenberg, D., Schneweis, D.J., Hiromasa, Y., Tomich, J.M., Whitfield, A.E., 2012. Proteomic analysis of Frankliniella occidentalis and differentially expressed proteins in response to tomato spotted wilt virus infection. J. Virol. 86, 8793-809. doi:10.1128/JVI.00285-12

Bandla, M.D., Campbell, L.R., Ullman, D.E., Sherwood, J.L., 1998. Interaction of Tomato Spotted Wilt Tospovirus (TSWV) Glycoproteins with a Thrips Midgut Protein, a Potential Cellular Receptor for TSWV. Phytopathology 88, 98-104. doi:10.1094/PHYTO.1998.88.2.98

Bandyopadhyay, U., Kaushik, S., Varticovski, L., Cuervo, A.M., 2008. The ChaperoneMediated Autophagy Receptor Organizes in Dynamic Protein Complexes at the Lysosomal Membrane. Mol. Cell. Biol. 28, 5747-5763. doi:10.1128/MCB.02070-07 
Barillas-Mury, C., Wizel, B., Han, Y.S., 2000. Mosquito immune responses and malaria transmission: lessons from insect model systems and implications for vertebrate innate immunity and vaccine development. Insect Biochem. Mol. Biol. 30, 429-42. doi:10.1016/s0965-1748(00)00018-7

Basak, S., Kim, H., Kearns, J.D., Tergaonkar, V., Dea, E.O., Werner, S.L., Benedict, C.A., Ware, C.F., Ghosh, G., Inder, M., Hoffmann, A., 2007. A fourth IкB protein within the NF-אB signaling module Soumen. Cell 128, 369-381.

Belliure, B., Janssen, A., Maris, P.C., Peters, D., Sabelis, M.W., 2005. Herbivore arthropods benefit from vectoring plant viruses. Ecol. Lett. 8, 70-79. doi:10.1111/j.14610248.2004.00699.x

Belliure, B., Janssen, A., Sabelis, M.W., 2008. Herbivore benefits from vectoring plant virus through reduction of period of vulnerability to predation. Oecologia $156,797-806$. doi:10.1007/s00442-008-1027-9

Berth, M., Moser, F.M., Kolbe, M., Bernhardt, J., 2007. The state of the art in the analysis of two-dimensional gel electrophoresis images. Appl. Microb. Biotechnol. 76, 1223-1243. doi:10.1007/s00253-007-1128-0

Bieback, K., Lien, E., Klagge, I.M., Avota, E., Duprex, W.P., Wagner, H., Kirschning, C.J., Meulen, V., Schneider-schaulies, S., 2002. Hemagglutinin Protein of Wild-Type Measles Virus Activates Toll-Like Receptor 2 Signaling. J. Virol. 76, 8729-8736. doi:10.1128/JVI.76.17.8729

Burzyn, D., Rassa, J.C., Kim, D., Nepomnaschy, I., Ross, S.R., Piazzon, I., 2004. Toll-Like Receptor 4-Dependent Activation of Dendritic Cells by a Retrovirus. J. Virol. 78, 576584. doi:10.1128/JVI.78.2.576

Cerenius, L., Kawabata, S., Lee, B.L., Nonaka, M., 2010. Proteolytic cascades and their involvement in invertebrate immunity. Trends Biochem. Sci. 35, 575-583. doi:10.1016/j.tibs.2010.04.006 
Česena, M.H., Pegana, K., Špesa, A., Turka, B., 2012. Lysosomal pathways to cell death and their therapeutic applications. Exp. Cell Res. 318, 1245-1251. doi:10.1016/j.yexcr.2012.03.005

Christensen, B.M., Tracy, J.W., Tracy, W., 1989. Arthropod-Transmitted Parasites : Mechanisms of Immune Interaction Linked references are available on JSTOR for this article : Am. Zool. 29, 387-398.

Colditz, F., Nyamsuren, O., Niehaus, K., Eubel, H., Braun, H.-P., Krajinski, F., 2004. Proteomic approach: Identification of Medicago truncatula proteins induced in roots after infection with the pathogenic oomycete Aphanomyces euteiches. Plant Mol. Biol. 55, 109-120. doi:10.1007/s11103-004-0499-1

Compton, T., Kurt-jones, E.A., Boehme, K.W., Belko, J., Latz, E., Golenbock, D.T., Finberg, R.W., 2003. Human Cytomegalovirus Activates Inflammatory Cytokine Responses via CD14 and Toll-Like Receptor 2. J. Virol. 77, 4588-4596. doi:10.1128/JVI.77.8.4588

Cuervo, A., Knecht, E., Terlecky, S., Dice, J., 1995. Activation proteolysis of a selective pathway of lysosomal in rat liver by prolonged starvation. Am. J. Physiol. 269, 200-208. de Medeiros, R.B., Resende, R.D.O., de Avila, A.C., 2004. The plant virus Tomato Spotted Wilt Tospovirus activates the immune system of its main insect vector, Frankliniella occidentalis. J. Virol. 78, 4976-82. doi:10.1128/JVI.78.10.4976

de Medeiros, R.B., Ullman, D.E., Sherwood, J.L., German, T.L., 2000. Immunoprecipitation of a 50-kDa protein: a candidate receptor component for tomato spotted wilt tospovirus (Bunyaviridae) in its main vector, Frankliniella occidentalis. Virus Res. 67, 109-18. doi:http://dx.doi.org/10.1016/S0168-1702(00)00123-4

Doyle, S.L., Neill, L.A.J.O., 2006. Toll-like receptors : From the discovery of NFkB to new insights into transcriptional regulations in innate immunity. Biochem. Pharmacol. 72, 1102-1113. doi:10.1016/j.bcp.2006.07.010

Georgel, P., Jiang, Z., Kunz, S., Janssen, E., Mols, J., Hoebe, K., Bahram, S., Oldstone, 
M.B.A., Beutler, B., 2007. Vesicular stomatitis virus glycoprotein $\mathrm{G}$ activates a specific antiviral Toll-like receptor 4-dependent pathway. Virology 362, 304-313. doi:10.1016/j.virol.2006.12.032

Glickman, M.H., Ciechanover, A., 2002. The Ubiquitin-Proteasome Proteolytic Pathway: Destruction for the Sake of Construction. Physiol. Rev. 82, 373-428.

Hayden, M.S., West, A.P., Ghosh, S., 2006. NF-кB and the immune response. Oncogene 25, 6758-6780. doi:10.1038/sj.onc.1209943

Hoffmann, J. a, Kafatos, F.C., Janeway, C. a, Ezekowitz, R. a, 1999. Phylogenetic perspectives in innate immunity. Science 284, 1313-1318. doi:10.1126/science.284.5418.1313

Hoffmann, J. a, Reichhart, J.-M., 2002. Drosophila innate immunity: an evolutionary perspective. Nat. Immunol. 3, 121-6. doi:10.1038/ni0202-121

Karin, M., Ben-neriah, Y., 2000. Phosphorylation meets ubiquitination: the control of NF-kB activity". Annu. Rev. Immunol. Immunol. 18, 621-663.

Kikkert, M., Meurs, C., van de Wetering, F., Dorfmüller, S., Peters, D., Kormelink, R., Goldbach, R., 1998. Binding of Tomato Spotted Wilt Virus to a 94-kDa Thrips Protein. Phytopathology 88, 63-69. doi:10.1094/PHYTO.1998.88.1.63

Kimura, Y., Tanaka, K., 2010. Regulatory mechanisms involved in the control of ubiquitin homeostasis. J. Biochem. 147, 793-798. doi:10.1093/jb/mvq044

Klodmann, J., Sunderhaus, S., Nimtz, M., Jansch, L., Braun, H., 2010. Internal Architecture of Mitochondrial Complex I from Arabidopsis thaliana. Plant Cell 22, 797-810. doi:10.1105/tpc.109.073726

Komander, D., Rape, M., 2012. The Ubiquitin Code. Annu. Rev. Biochem. 81, 203-229. doi:10.1146/annurev-biochem-060310-170328

Lavine, M.D., Strand, M.R., 2002. Insect hemocytes and their role in immunity. Insect Biochem. Mol. Biol. 32, 1295-309. 
Livolsi, A., Busuttil, V., Imbert, V., Abraham, R., Peyron, J., 2001. Tyrosine phosphorylation-dependent activation of NF- $\kappa \mathrm{B}$ Requirement for p56 LCK and ZAP-70 protein tyrosine kinases. Eur. J. Biochem. 268, 1508-1515.

Lo, J.C., Basak, S., James, E.S., Quiambo, R.S., Kinsella, M.C., Alegre, M., Weih, F., Franzoso, G., 2006. Coordination between NF- $\mathrm{BB}$ family members p50 and p52 is essential for mediating LTßR signals in the development and organization of secondary lymphoid tissues. Blood 107, 1048-1056. doi:10.1182/blood-2005-06-2452.Supported

Lorenz, C., Rolletschek, H., Sunderhaus, S., Braun, H., 2014. Brassica napus seed endosperm — Metabolism and signaling in a dead end tissue. J. Proteomics 108, 382-426. doi:10.1016/j.jprot.2014.05.024

Majzoub, K., Hafirassou, M.L., Meignin, C., Goto, A., Marzi, S., Fedorova, A., Hoffmann, J.A., Martin, F., Baumert, T.F., Schuster, C., Verdier, Y., 2014. Guanine nucleotidebinding subunit beta-like. Cell 159, 1086-1095. doi:10.1016/j.cell.2014.10.041

Mcdowell, G.S., Philpott, A., 2013. Non-canonical ubiquitylation : Mechanisms and consequences. Int. J. Biochem. Cell Biol. 45, 1833-1842. doi:10.1016/j.biocel.2013.05.026

Mihr, C., Braun, H., 2003. Proteomics in plant biology, in: Michael, P. (Ed.), Handbook of Proteomics Methods. Humana Press Inc, Totowa, pp. 409-41.

Mizushima, N., 2007. Autophagy: process and function. Genes Dev. 2861-2873. doi:10.1101/gad.1599207.eralize

Moritz, G., Kumm, S., Mound, L., 2004. Tospovirus transmission depends on thrips ontogeny. Virus Res. 100, 143-9. doi:10.1016/j.virusres.2003.12.022

Mukhopadhyay, D., Riezman, H., 2007. Proteasome-Independent Functions of Ubiquitin in Endocytosis and Signaling. Science (80-. ). 315, 201-206.

Nagata, T., Inoue-Nagata, A.K., Smid, H.M., Goldbach, R., Peters, D., 1999. Tissue tropism related to vector competence of Frankliniella occidentalis for tomato spotted wilt 
tospovirus. J. Gen. Virol. 80 ( Pt 2), 507-15.

Nagata, T., Inoue-Nagata, A.K., van Lent, J., Goldbach, R., Peters, D., 2002. Factors determining vector competence and specificity for transmission of Tomato spotted wilt virus. J. Gen. Virol. 83, 663-71.

Naidu, R.A., Sherwood, J.L., Deom, C.M., 2008. Characterization of a vector-nontransmissible isolate of Tomato spotted wilt virus. Plant Pathol. 57, 190-200. doi:10.1111/j.1365-3059.2007.01707.x

Nakamoto, M., Moy, R.H., Xu, J., Bambina, S., Yasunaga, A., Shelly, S.S., Gold, B., Cherry, S., 2012. Virus recognition by Toll-7 activates antiviral autophagy in Drosophila. Immunity 36, 658-67. doi:10.1016/j.immuni.2012.03.003

Nault, L.R., 1994. Planthoppers: Their Ecology and Management, in: Denno, R.F., Perfect, T.J. (Eds.), . Springer US, Boston, MA, pp. 429-448. doi:10.1007/978-1-4615-2395$6 \_13$

Nelson, D.E., Ihekwaba, A.E.C., Elliott, M., Johnson, J.R., Gibney, C.A., Foreman, B.E., Nelson, G., See, V., Horton, C.A., Spiller, D.G., Edwards, S.W., McDowell, H.P., Unitt, J.F., Sullivan, E., Grimley, R., Benson, N., Broomhead, D., Kell, D.B., White, M.R.H., 2004. Oscillations in NF-кB Signaling Control the Dynamics of Gene Expression. Science (80-. ). 306, 704-708.

Neuhoff, V., Stamm, R., Eibl, H., 1985. Clear background and highly sensitive protein staining with Coomassie Blue dyes in polyacrylamide gels : A systematic analysis. Electrophoresis 6, 427-448.

Neuhoff, V., Stamm, R., Pardowitz, I., Arold, N., Ehrhardt, W., Taube, D., 1990. Essential problems in quantification of proteins following colloidal staining with Coomassie Brilliant Blue dyes in polyacrylamide gels , and their solution. Electrophoresis 11, 101117.

Ogada, P., Debener, T., Poehling, H., 2016. Inheritance genetics of the trait vector 
competence in Frankliniella occidentalis ( Western flower thrips ) in the transmission of Tomato spotted wilt virus. Ecol. Evol. 1-10. doi:10.1002/ece3.2484

Ogada, P.A., Maiss, E., Poehling, H.-M., 2013. Influence of tomato spotted wilt virus on performance and behaviour of western flower thrips ( Frankliniella occidentalis ). J. Appl. Entomol. 137, 488-498. doi:10.1111/jen.12023

Ogada, P.A., Moualeu, D.P., Poehling, H., 2016. Predictive Models for Tomato Spotted Wilt Virus Spread Dynamics, Considering Frankliniella occidentalis Specific Life Processes as Influenced by the Virus. PLoS One 11, 1-20. doi:10.1371/journal.pone.0154533

Papers, J.B.C., Schnell, J.D., Hicke, L., 2003. Non-traditional Functions of Ubiquitin and Ubiquitin-binding Proteins. J. Biol. Chem. 278, 35857-35861. doi:10.1074/jbc.R300018200

Paskewitz, S., Christensen, B., 1996. Immune responses of vectors., in: Beaty, B., Marquardt, W. (Eds.), The Biology of Disease Vectors. University Press of Colorado, Niwot, Colorado, pp. 371-392.

Richetta, C., Faure, M., Lyon, U. De, F-, L., 2013. Autophagy in antiviral innate immunity. Cell. Microbiol. 15, 368-376. doi:10.1111/cmi.12043

Riley, D.G., Pappu, H.R., 2004. Tactics for Management of Thrips (Thysanoptera: Thripidae) and Tomato Spotted Wilt Virus in Tomato. Hortic. Entomol. 97, 1648-1658.

Shalileh, S., Ogada, P.A., Moualeu, D.P., Poehling, H.M., 2016. Manipulation of Frankliniella occidentalis by tomato spotted wilt virus (Tospovirus) via the host plant nutrients to enhance transmission and spread of the virus. Environ. Entomol. 1-8. doi:http://dx.doi.org/10.1093/ee/nvw102

Shelly, S., Lukinova, N., Bambina, S., Berman, A., Cherry, S., 2009. Autophagy is an essential component of Drosophila immunity against vesicular stomatitis virus. Immunity 30, 588-598. doi:10.1016/j.immuni.2009.02.009.Autophagy

Shrestha, A., Srinivasan, R., Riley, D.G., Culbreath, A.K., 2012. Direct and indirect effects of 
a thrips-transmitted Tospovirus on the preference and fitness of its vector, Frankliniella fusca. Entomol. Exp. Appl. 145, 260-271. doi:10.1111/eea.12011

Song, C., Weichbrodt, C., Salnikov, E.S., Dynowski, M., Forsberg, B.O., Bechinger, B., Steinem, C., de Groot, B.L., Zachariae, U., Zeth, K., 2013. Crystal structure and functional mechanism of a human antimicrobial membrane channel. Proc. Natl. Acad. Sci. U. S. A. 110, 4586-4591. doi:10.1073/pnas.1214739110

Stafford, C.A., Walker, G.P., Ullman, D.E., 2011. Infection with a plant virus modifies vector feeding behavior. Proc. Natl. Acad. Sci. U. S. A. 108, 9350-9355. doi:10.1073/pnas.1100773108

Stumpf, C.F., Kennedy, G.G., 2007. Effects of tomato spotted wilt virus ( TSWV ) isolates , host plants , and temperature on survival, size, and development time of Frankliniella fusca. Entomol. Exp. Appl. 114, 215-225. doi:10.1111/j.1570-7458.2007.00541.x

Turcu, F.E.R., Ventii, K.H., Wilkinson, K.D., 2009. Regulation and Cellular Roles of Ubiquitin-specific Deubiquitinating Enzymes. Annu. Rev. Biochem. 78, 363-397. doi:10.1146/annurev.biochem.78.082307.091526.Regulation

Ullman, D., German, T., Sherwood, J., 1993. Tospovirus replication in insect vector cells: Immunocytochemical evidence that the nonstructural protein encoded by the S RNA of tomato spotted wilt. Phytopathology.

Ullman, D., Sherwood, J., German, T., 1997. Thrips as a vector of plant pathogens. In Thrips as Crop Pests", in: Lewis, T. (Ed.), Thrips as Crop Pests. CAB International, Wallingford, U.K.

UniProtKB/Swiss-Prot, 2015. http://www.uniprot.org/uniprot/Q6EWQ7 [WWW Document]. URL http://www.uniprot.org/uniprot/Q6EWQ7 (accessed 5.4.16).

Vermaak, D., Malik, H.S., 2009. Multiple Roles for Heterochromatin Protein 1 Genes in Drosophila. Annu. Rev. Genet. 43, 467-492. doi:10.1146/annurev-genet-102108-134802 Vijayaraghavan, S., Liberty, G.A., Mohan, J., Winfrey, V.P., Olson, G.E., Carr, D.W., 1999. 
Isolation and Molecular Characterization of AKAP110, a Novel , Sperm-Specific

Protein Kinase A-Anchoring Protein. Mol. Endocrinol. 13, 705-717.

Waltenbaugh, C., Doan, T., Melvold, R., Viselli, S., 2008. Lippincott's Illustrated reviews, in: Wolters Kluwer (Ed.), Immunology. Health/Lippincott Williams \& Wilkins, Philadelphia, p. 17.

Washburn, J.O., Kirkpatrick, B.A., Volkman, L.E., 1996. Insect protection against baculoviruses. Nature. doi:10.1038/383767a0

Whitfield, A., Kumar, N., Rotenberg, D., Ullman, D., Wyman, E., Zietlow, C., Willis, D., German, T., 2008. A soluble form of the Tomato spotted wilt virus (TSWV) glycoprotein $\mathrm{G}(\mathrm{N})(\mathrm{G}(\mathrm{N})-\mathrm{S})$ inhibits transmission of TSWV by Frankliniella occidentalis. Phytopathology 98, 45-50. doi:10.1094/PHYTO-98-1-0045

Whitfield, A.E., Ullman, D.E., German, T.L., 2005. Tospovirus-Thrips Interactions. Annu. Rev. Phytopathol. 43, 459-489. doi:10.1146/annurev.phyto.43.040204.140017

Wijkamp, I., Almarza, N., Goldbach, R., Peters, D., 1995. Distinct Levels of Specificity in Thrips Transmission of Tospoviruses. Phytopathology. doi:10.1094/Phyto-85-1069

Wilkinson, K.D., Ciechanover, A., Rose, I.A., 2005. The discovery of ubiquitin-dependent proteolysis. Proc. Natl. Acad. Sci. U. S. A. 102, 15280-15282.

Zeth, K., 2013. Structure and mechanism of human antimicrobial peptide dermcidin and its antimicrobial potential. Formatex 1333-1342. 


\section{Figure}

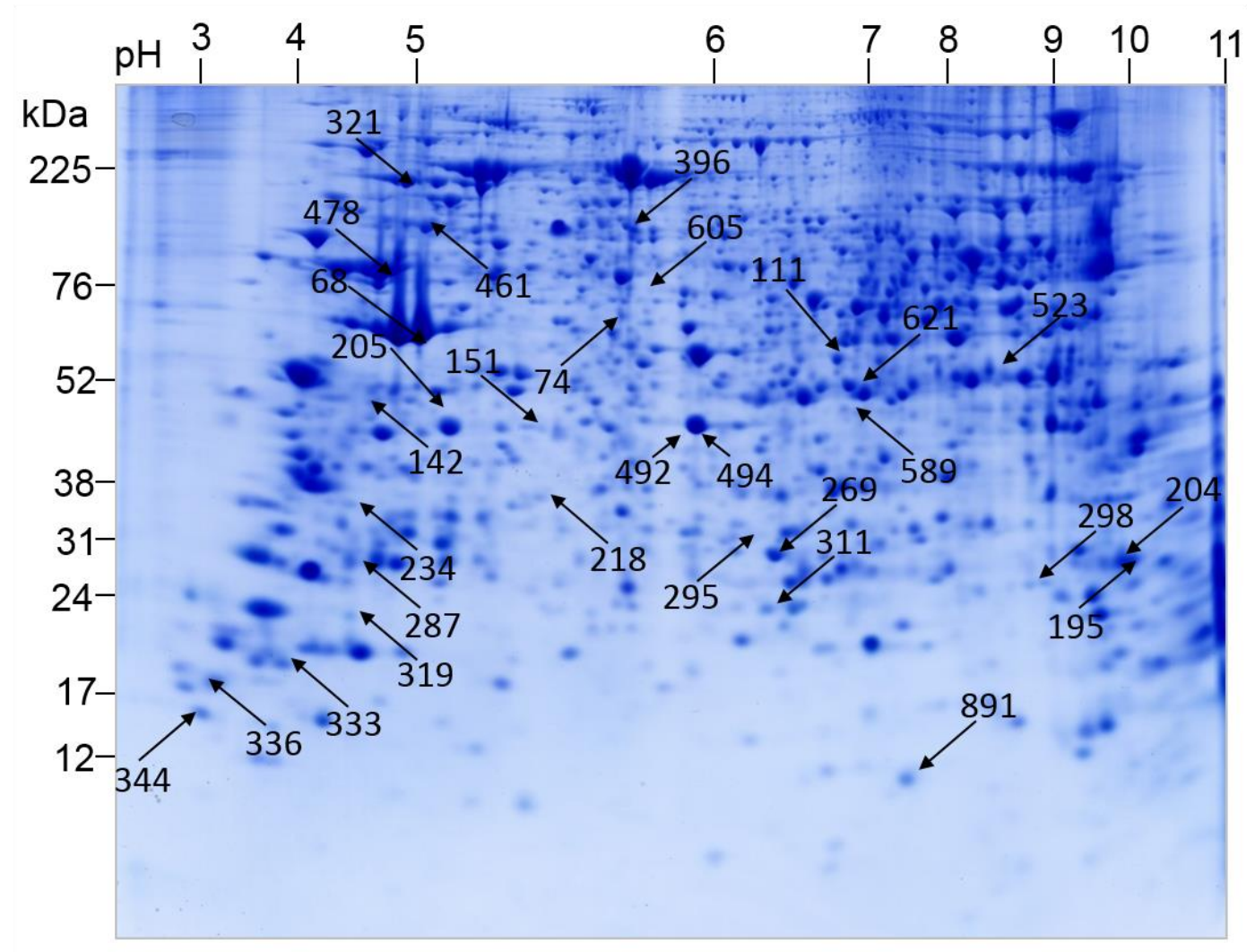

Figure 1: Two-dimensional reference gel map for $F$. occidentalis proteome. A 3-11 nonlinear immobilized $\mathrm{pH}$ gradient (IPG) strip was used to separate total soluble proteins by isoelectric focusing (pIs are given above the $2 \mathrm{D}$ gel), followed by their separation according to molecular mass by SDS-PAGE (the masses of standard proteins are given to the left of the 2D gel). Coomassie brilliant blue G250 was used to stain the gels. The arrows indicate spots which are significantly altered in volume, and the numbers represent spot IDs (www.gelmap.de/1290 password: FoProt). 
Table 1: Protein identifications from spots with changed volumes between the TSWV exposed and the non-exposed ( 24 hours) F. occidentalis L1. Student's ttest ( $\mathrm{p}$-value $\leq 0.05$ ) was used to determine significant changes in spot volume between the treatments based on normalized relative spot volumes. Changes in spot volume $\geq 1.5$ were considered to represent alterations. MASCOT search algorithm was used for protein identification (www.matrixscience.com) against the (i) Ensembl Metazoa (www.metazoa.ensembl.org), (ii) Flybase (www.flybase.org), (iii) SwissProt (www.uniprot.org), and (iv) NCBInr (www.ncbi.nig.gov) databases. A) Proteins of increased abundance in F. occidentalis after the 24-hour exposure to TSWV, and B) Proteins of decreased abundance in $F$. occidentalis after the 24-hour exposure to TSWV (www.gelmap.de/1290 password: FoProt).

A) Proteins of increased abundance in $F$. occidentalis after the 24-hour exposure to TSWV

\begin{tabular}{|c|c|c|c|c|c|c|c|}
\hline ID & Accession & Name & Organism & $\begin{array}{c}\text { MM calc } \\
{[\mathrm{kDa}]}\end{array}$ & $\begin{array}{c}\mathrm{pI} \\
\text { calc }\end{array}$ & $\begin{array}{c}\text { MASCOT } \\
\text { Score }\end{array}$ & $\begin{array}{c}\text { Sequence } \\
\text { Coverage } \\
(\%)\end{array}$ \\
\hline \multicolumn{8}{|c|}{ Structural protein } \\
\hline 74 & ARP2_DROME & Actin-related protein 2 & Drosophila melanogaster & 44.7 & 5.8 & 293 & 16 \\
\hline 74 & ACT2_MOLOC & Actin, muscle-type & Molgula oculata & 42.2 & 5 & 275 & 17 \\
\hline 74 & ACT1_BACDO & Actin, indirect flight muscle & Bactrocera dorsalis & 41.7 & 5.2 & 267 & 21 \\
\hline \multicolumn{8}{|c|}{ Anatomical development } \\
\hline 589 & HORN_HUMAN & Hornerin & Homo sapiens & 282.2 & 10.4 & 39 & 1 \\
\hline 333 & HAND2_DANRE & Heart- and neural crest derivatives & Danio rerio & 23.2 & 9.7 & 41 & 3 \\
\hline 205 & CATL_SARPE & Cathepsin L & Sarcophaga peregrina & 37.8 & 6 & 47 & 4 \\
\hline 333 & IDGF3_DROME & Chitinase-like protein & Drosophila melanogaster & 49.2 & 7.8 & 36 & 1 \\
\hline 74 & HDX_HUMAN & Highly divergent homeobox (DNA Binding) & Homo sapiens & 77.2 & 5.5 & 43 & 2 \\
\hline \multicolumn{8}{|c|}{ Translation } \\
\hline 111 & RLA0_CERCA & 60S acidic ribosomal protein $\mathrm{P} 0$ & Ceratitis capitata & 33.9 & 7.6 & 224 & 10 \\
\hline 111 & RLA0L_HUMAN & $60 \mathrm{~S}$ acidic ribosomal protein $\mathrm{P} 0$-like & Homo sapiens & 34.3 & 5.3 & 112 & 6 \\
\hline 111 & RLA0_C̄AEEL & $60 \mathrm{~S}$ acidic ribosomal protein $\mathrm{P} 0$ & Caenorhabditis elegans & 33.8 & 6.3 & 69 & 6 \\
\hline 111 & SYEP_DROME & Bifunctional glutamate/proline--tRNA ligase & Drosophila melanogaster & 189.3 & 9.4 & 42 & 1 \\
\hline 195 & RL12_BOVIN & $60 \mathrm{~S}$ ribosomal protein L12 & Bos taurus & 17.8 & 10.3 & 56 & 5 \\
\hline 204 & RL12 BOVIN & $60 S$ ribosomal protein L12 & Bos taurus & 17.8 & 10.3 & 53 & 5 \\
\hline 204 & EIF3J_DROVI & Eukaryotic translation initiation factor 3 , subunit $\mathrm{J}$ & Drosophila virilis & 27 & 4.6 & 41 & 4 \\
\hline 287 & IF5A1_BOVIN & Eukaryotic translation initiation factor 5A-1, & Bos taurus & 16.8 & 4.9 & 49 & 5 \\
\hline 523 & RL5_LYSTE & $60 \mathrm{~S}$ ribosomal protein & Lysiphlebus testaceipes & 34.4 & 10.1 & 48 & 5 \\
\hline 621 & RLA0_CERCA & $60 \mathrm{~S}$ acidic ribosomal protein & Ceratitis capitata & 33.9 & 7.6 & 150 & 8 \\
\hline \multicolumn{8}{|c|}{ Stress response } \\
\hline 74 & HSP7D_DROME & Heat shock $70 \mathrm{kDa}$ protein & Drosophila melanogaster & 71.1 & 5.2 & 317 & 11 \\
\hline 74 & HSP7C_DROME & Heat shock $70 \mathrm{kDa}$ protein & Drosophila melanogaster & 72.2 & 5.1 & 273 & 6 \\
\hline 74 & HSP7E_DROME & Heat shock $70 \mathrm{kDa}$ protein & Drosophila melanogaster & 74 & 6 & 209 & 8 \\
\hline \multicolumn{8}{|c|}{ Signaling } \\
\hline
\end{tabular}




\begin{tabular}{|c|c|c|c|c|c|c|c|}
\hline 151 & FIBA_CHICK & Fibrinogen alpha chain & Gallus gallus & 82.4 & 5.6 & 39 & 1 \\
\hline 195 & AKAP3_MOUSE & A-kinase anchor protein 3 & Mus musculus & 95.5 & 5.9 & 40 & 1 \\
\hline 195 & UBIQ_CAMDR & Ubiquitin & Camelus dromedarius & 8.6 & 7.6 & 83 & 24 \\
\hline 621 & VCIP1_MOUSE & Valosin-containing interacting protein 135 (VCIP135) & Mus musculus & 134.4 & 6.8 & 42 & 1 \\
\hline 621 & GBLP_DROME & Guanine nucleotide-binding subunit beta-like & Drosophila melanogaster & 35.6 & 7.9 & 53 & 3 \\
\hline \multicolumn{8}{|c|}{ Defense response } \\
\hline 298 & REV1_HUMAN & DNA repair protein REV1 & Homo sapiens & 138.2 & 9.5 & 39 & 0 \\
\hline 74 & HUGĀB_VESVU & Inactive hyaluronidase B & Vespula vulgaris & 40 & 9.8 & 38 & 2 \\
\hline 195 & DCD_HUMAN & Dermcidin & Homo sapiens & 11.3 & 6.1 & 44 & 10 \\
\hline 195 & DCD_HUMAN & Dermcidin & Homo sapiens & 11.3 & 6.1 & 37 & 10 \\
\hline 311 & UBP36_HUMAN & Ubiquitin carboxyl-terminal hydrolase 36 & Homo sapiens & 122.6 & 10.4 & 52 & 1 \\
\hline 311 & HP1_DROME & Heterochromatin protein 1 & Drosophila melanogaster & 23.2 & 4.9 & 36 & 4 \\
\hline \multicolumn{8}{|c|}{ Nucleotide metabolism } \\
\hline 523 & GMPR_ASCSU & GMP reductase & Ascaris suum & 39.2 & 6.8 & 76 & 3 \\
\hline 621 & GBLP_DROME & Guanine nucleotide-binding subunit beta-like & Drosophila melanogaster & 35.6 & 7.9 & 53 & 3 \\
\hline \multicolumn{8}{|c|}{ Cellular lipid metabolic process (NADP) } \\
\hline 621 & ALD1_MOUSE & Aldose reductase-related protein 1 & Mus musculus & 36 & 6.9 & 56 & 3 \\
\hline \multicolumn{8}{|c|}{ Actin binding protein } \\
\hline 621 & CORO7_RAT & Coronin-7 (Fragment) & Rattus norvegicus & 48.9 & 5.3 & 41 & 2 \\
\hline
\end{tabular}

B) Proteins of decreased abundance in $F$. occidentalis after the 24-hour exposure to TSWV

\begin{tabular}{|c|c|c|c|c|c|c|c|}
\hline ID & Accession & Name & Organism & $\begin{array}{l}\text { MM calc } \\
{[\mathrm{kDa}]}\end{array}$ & $\begin{array}{l}\mathrm{pI} \\
\text { calc }\end{array}$ & $\begin{array}{l}\text { MASCOT } \\
\text { Score }\end{array}$ & $\begin{array}{l}\text { Sequence } \\
\text { Coverage }(\%) \\
\end{array}$ \\
\hline \multicolumn{8}{|c|}{ Structural protein } \\
\hline 68 & ACT5_BACDO & Actin-5, muscle-specific & Bactrocera dorsalis & 41.7 & 5.2 & 1332 & 50 \\
\hline 68 & ACT2_MOLOC & Actin, muscle-type & Molgula oculata & 42.2 & 5 & 1308 & 51 \\
\hline 68 & ACTB BOVIN & Actin, cytoplasmic 1 & Bos taurus & 41.7 & 5.2 & 1251 & 49 \\
\hline 68 & ACTB_ORYLA & Actin, cytoplasmic 1 & Oryzias latipes & 41.7 & 5.2 & 1199 & 49 \\
\hline 68 & ACTG_ANSAN & Actin, cytoplasmic 2 & $\begin{array}{l}\text { Anser anser } \\
\text { Strongylocentrotus }\end{array}$ & 41.9 & 5.3 & 1192 & 47 \\
\hline 68 & ACTA_STRPU & Actin, cytoskeletal 1A & $\begin{array}{l}\text { purpuratus } \\
\text { Branchiostoma }\end{array}$ & 41.8 & 5.2 & 1153 & 42 \\
\hline 68 & ACTC_BRALA & Actin, cytoplasmic & lanceolatum & 41.7 & 5.1 & 1144 & 39 \\
\hline 68 & ACTBL_HUMAN & Beta-actin-like protein 2 & Homo sapiens & 42 & 5.3 & 499 & 22 \\
\hline 396 & HORN_HUMAN & Hornerin & Homo sapiens & 282.2 & 10.4 & 85 & 2 \\
\hline $478 \mathrm{a}$ & TBAT_ONCMY & Tubulin alpha chain, testis-specific & Oncorhynchus mykiss & 50 & 4.8 & 1155 & 42 \\
\hline $478 \mathrm{a}$ & TBA1_DROME & Tubulin alpha- 1 chain & Drosophila melanogaster & 49.9 & 4.9 & 1151 & 42 \\
\hline
\end{tabular}


478a TBA3_HOMAM

478a TBA1_HOMAM

478a TBB_PIG

142 ACTA_BOVIN
Tubulin alpha-3 chain

Tubulin alpha- 1 chain

Tubulin beta chain

Actin, aortic smooth muscle
Homarus americanus

Homarus americanus

Sus scrofa

Bos taurus

Protein processing

Sugar metabolism

605 ENO_DROME

68 ACTBL_HUMAN

478a ATPB DROME

478a VATB_DROME

461 ATPB_DROME ATP synthase subunit beta, mitochondrial

Amino acid metabolism

605 SAHH_ANOGA Adenosylhomocysteinase

605 SAHHA_XENLA Adenosylhomocysteinase A

Bos taurus

Energy metabolism

Beta-actin-like protein 2

ATP synthase subunit beta, mitochondrial

V-type proton ATPase subunit B

Homo sapiens

Anopheles gambiae

Xenopus laevis
Drosophila melanogaster

Drosophila melanogaster

Drosophila melanogaster

Drosophila melanogaster

$\begin{array}{llll}50 & 4.8 & 806 & 28 \\ 50 & 4.9 & 776 & 25 \\ 49.8 & 4.6 & 275 & 14 \\ 42 & 5.1 & 47 & 3\end{array}$

72.4

$4.9 \quad 243$

\section{Cell cycle}

Mus musculus
47.6

47.7

65.3
$9.4 \quad 186$

5.3499

$5 \quad 705$

$5.1 \quad 52$

$5.5 \quad 82$

$6 \quad 53$

82
53
48

48

